\title{
COVER ESSAY
}

\section{Poverty and tobacco}

\author{
Joy de Beyer, Chris Lovelace, Ayda Yürekli
}

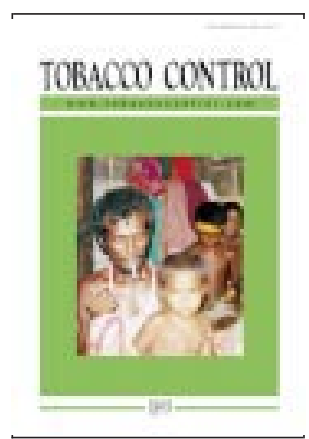

Concern about the harm that tobacco use causes usually focuses on the risks of serious illness and premature death that smokers and their families face. The statistics are probably well known to readers of this journal-an estimated 4 million deaths are caused by tobacco each year, with the figure expected to reach 10 million per year by 2030 given current trends in tobacco use. ${ }^{1}$ The proportion of that burden borne by people living in low and middle income countries is rapidly increasing from $50 \%$ to $70 \%$. Countries still grappling with infectious diseases traditionally associated with low incomes, increasingly also face a rising epidemic of cancers, and respiratory and circulatory diseases caused by tobacco.

Many (but not all) of the risks to health and life caused by tobacco consumption develop over a long period, and take decades to become fully evident. But tobacco use can also inflict immediate harm on users and their families, damage that is wreaked little by little each day, and is usually overlooked. This is the damage that is done when scarce family resources are spent on tobacco products instead of on food, or other essential needs. Even a small diversion of resources of poor families who live at or below the edge of poverty can have a significant impact on their health and nutrition. The article by Efroymson and her colleagues in this journal makes an important and new contribution in explaining why communities, governments, donors, health professionals, and others who care about reducing poverty and improving lives should work to reduce tobacco use. $^{2}$

\section{Smoking can worsen malnutrition}

Instead of going up in smoke (and carcinogens), the money might instead be buying desperately needed additional calories and nutrients. Efroymson and colleagues show that "If poor people did not smoke . . potentially 10.5 million fewer people would be malnourished in Bangladesh." "Each tobacco user represents one or more people-whether the smoker or his or her spouse or child-who is needlessly going hungry." Of course, reducing malnutrition is a complex challenge, and additional income does not translate in any simple way into nutritional improvements. Clean water, the intra-household distribution of food, feeding and child care practices, and many other factors are relevant too. But the complexities should not obscure the key point - an additional 800 calories a day could potentially make an enormous difference to the

nutritional status and health of children (or others) in households that suffer from severe malnutrition, in Bangladesh and elsewhere.

Bangladesh is one of the poorest countries in the world, and in 1996 (the latest year for which data are available) nearly $30 \%$ of her 120 million people lived on less than US $\$ 1$ a day. ${ }^{3}$ For the 1.2 billion people worldwide who struggle to live on less than $\$ 1$ a day, every penny matters. In the Bangladesh survey, on average for all households, only $2.8 \%$ of total expenditures were allocated for tobacco products, and this ranged from $1.5 \%$ for the poorest households to $4.5 \%$ for those with the highest incomes. Yet even these tiny fractions (which, given low income levels, are also very small absolute amounts) have a very high opportunity cost.

Tobacco expenditure percentages are similar in several other countries. In Egypt in 1997, tobacco products accounted for just less than $2 \%$ of total household expenditures for all but the richest quintile of households, where it rose to $2.8 \%$ (Sayginsoy Ö, unpublished work for the World Bank, in progress). The national household expenditure survey in India in 1986-87 found that between $2.5-4 \%$ of all household expenditures were for tobacco, pan, and intoxicants; the percentage was highest for the lowest income urban households (Basheer RA, unpublished data, May 1993). For all households that included at least one smoker, the lowest income quartile in South Africa spent $4.7 \%$ of their income on cigarettes in 1995, with the percentage steadily decreasing for higher income groups, to between $0.6-1.3 \%$ for the highest income quartiles in the various race groups (Van Walbeek CP, unpublished data 2000).

But in many countries, the proportion of total household expenditure that goes on tobacco products is much higher. Low income households with at least one smoker in Bulgaria spent $10.4 \%$ of their total income on tobacco products in 1995 (Sayginsoy Ö et al, unpublished data, 2000). Urban households in Tibet spent $5.5 \%$ of their monthly disposable income on tobacco products in 1992. In China, smokers in 2716 households surveyed in the Minhang district reported spending 17\% of household income on cigarettes. ${ }^{4}$

The trends in expenditures on tobacco among poor people in some developing countries are also extremely worrying. In Indonesia, for example, tobacco expenditure has grown fastest among the poorest groups. In 1981, the lowest income group spent 210 
rubiah per capita on tobacco, $9 \%$ of their total expenditure. This rose to 1278 rubiah, $15 \%$ of total expenditure in 1996 (World Bank estimates using statistics published by the National Statistical Office of Indonesia). Greater efforts to reduce tobacco use among poor people are clearly needed.

\section{Smoking exacerbates poverty in several other ways too}

Beyond the short term links between poverty and tobacco use, there are also long term effects that arise because of the higher risks of illness that tobacco users face, and the particular vulnerability of poor families to illness, especially of the breadwinner. In low income countries, very few people are covered by health insurance or unemployment benefits. Illness and death, and the consequent loss of the income of a breadwinner, can be devastating for a family living close to, or below, the poverty line. Many poor people have few or no assets, apart from their ability to work. The poorer, less educated and less skilled people are, the more likely it is that their livelihood entails physical work. When a breadwinner in a poor family becomes too ill to work, the family's food supplies and income often stop. Paying for treatment further impoverishes the family-when people who live on $\$ 1$ a day are ill, they may well have to choose between seeking care, and food for the family. Medical care may be inaccessible, requiring many hours of walking and waiting; the quality of care is highly variable, and drugs are often unavailable.
Episodes of ill health, the costs of health care, and premature death are frequently cited by poor people as their gravest concerns, and as the precipitating cause that pushes families into poverty. As part of a study using open ended participatory methods to talk with more than 20000 poor men and women from 23 countries, a content analysis of 125 case studies found that sickness or injury of a family member was by far the most frequent trigger for a downward slide into (worse) poverty. ${ }^{5}$ The implications of high prevalence of tobacco use among men with low education and low incomes, which raises their relative risks of serious diseases and premature death, are grave. Policies and interventions to help poor smokers quit, and to discourage others from starting, are an important part of national and international efforts to improve the health and well being of poor people.

1 World Bank. Curbing the epidemic: governments and the economics of tobacco control. Washington, DC: Development in Practice, 1999.

2 Efroymson D, Ahmed S, Townsend J, et al. Hungry for tobacco: an analysis of the economic impact of tobacco consumption on the poor in Bangladesh. Tobacco Control 2001;10:212-17.

3 World Bank. World development indicators 2000. Washington DC: World Bank, 2000.

4 Gong LY, Koplan JP, Feng W, et al. Cigarette smoking in China. Prevalence, characteristics and attitudes in Minhang District. FAMA 1995;274:1232-4.

5 Narayan D, Chambers R, Shah M, et al. Voices of the poor crying out for change. Washington DC: World Bank, 2000:253. 